\title{
Photoactive/Passive Molecular Glass Blends: an Efficient Strategy to Optimize Azomaterials for Surface Relief Grating Inscription
}

\author{
Audrey Laventure, ${ }^{\dagger}$ Jérémie Bourotte $^{\dagger}{ }^{\dagger}$ Jaana Vapaavuori, ${ }^{\dagger}$ Lucas Karperien, ${ }^{\ddagger}$ Ribal Georges Sa- \\ bat, $\ddagger$ Olivier Lebel ${ }^{\S}$ and Christian Pellerin ${ }^{\dagger, *}$ \\ †Département de chimie, Université de Montréal, Montréal, QC, $\mathrm{H}_{3} \mathrm{C}_{3} \mathrm{~J}_{7}$, Canada \\ ${ }_{\ddagger}$ Department of Physics, Royal Military College of Canada, Kingston, ON, $\mathrm{K}_{7} \mathrm{~K}{ }_{7} \mathrm{~B} 4$, Canada \\ ${ }^{\S}$ Department of Chemistry and Chemical Engineering, Royal Military College of Canada, Kingston, ON, K7K 7B4, \\ Canada
}

KEYWORDS. Surface relief grating, Photoactive materials, Azobenzene, Molecular glasses, Glass transition temperature, Photoinduced orientation.

\begin{abstract}
Irradiation of azomaterials causes various photophysical and photomechanical effects that can be exploited for the preparation of functional materials such as surface relief gratings (SRGs). Herein, we develop and apply an efficient strategy to optimize the SRG inscription process by decoupling, for the first time, the important effects of the azo content and glass transition temperature $\left(\mathrm{T}_{\mathrm{g}}\right)$. We prepare blends of a photoactive molecular glass functionalized with the azo Disperse Red 1 (gDRı) with a series of analogous photopassive molecular glasses. Blends with 10 and 40 mol\% of gDRı are completely miscible, present very similar optical properties, and cover a wide range of $\mathrm{T}_{\mathrm{g}}$ from below to well above ambient temperature. SRG inscription experiments show that the diffraction efficiency (DE), residual DE and initial inscription rate reach a maximum when $\mathrm{T}_{\mathrm{g}}$ is 25 to $40^{\circ} \mathrm{C}$ above ambient temperature for low to high azo content, respectively. Indeed, for a fixed $40 \mathrm{~mol} \%$ azo content, choosing the optimal $\mathrm{T}_{\mathrm{g}}$ enables doubling the SRG inscription rate and increasing DE sixfold. Moreover, a higher azo content enables higher DE for a similar $\mathrm{T}_{\mathrm{g}}$. Spectroscopy measurements indicate that the photoorientation of DRı and its thermal stability are maximal with $\mathrm{T}_{\mathrm{g}}$ around $70^{\circ} \mathrm{C}$, independent of the azo content. We conclude that the SRG potential of azomaterials depends on their capability to photo-orient but that the matrix rigidity eventually limits the inscription kinetics, leading to an optimal $\mathrm{T}_{\mathrm{g}}$ that depends on the azo content. This study exposes clear material design guidelines to optimize the SRG inscription process and the photoactivity of azomaterials.
\end{abstract}

\section{INTRODUCTION}

Azobenzene (azo) derivatives are well known to undergo repetitive trans to cis photoisomerizations that lead to photoinduced motion at length scales ranging from molecular to macroscopic. Azo-containing compounds are used in a wide range of applications, from light-controlled artificial molecular machines to photonic devices, ${ }^{1-3}$ but the details of their photomechanical response are not yet completely understood. In particular, it is still unclear how their molecular-scale trans-cis-trans photoisomerization can be translated into macroscopic motion at temperatures well below the bulk glass transition temperature $\left(\mathrm{T}_{\mathrm{g}}\right)$ where cooperative segmental motion of amorphous materials is extremely slow. This phenomenon, called photomobility, is notably encountered during the inscription of surface relief gratings (SRGs), a process first reported in $1995^{4,5}$ where a polarized light interference pattern creates a topological relief on azo-containing films. Contradictory theories and hypotheses have been proposed to tentatively explain this athermal mass transport, including a decrease of modulus and viscosity under illumination (photofluidization), ${ }^{6-8}$ a directional worm-like diffusion motion, ${ }^{9}$ a pressure gradient caused by the volume difference between the trans and cis isomers, ${ }^{10}$ and a re-orientation approach ${ }^{11}$ where the stress created by the photo-orientation of the azo moieties is larger than the yield stress of the material and thus allows its deformation without involving its photosoftening. ${ }^{12}$ Some recent experimental ${ }^{13}$ and computational $^{14-16}$ studies have confirmed that the trans-cis isomerization induces changes in the chromophore's molecular environment, either by creating additional free volume and/or by pushing the surrounding molecules in a cagebreaking process, which impacts the material motion potential.

In addition to the above-mentioned works, many efforts have been invested to optimize the SRG formation process by defining the role of different tunable experimental parameters, ${ }^{17-20}$ such as the azo content and its molecular structure, the $T_{g}$ of the matrix and its molecular weight, the thickness of the film, the polarization of the in- 
scribing and probe laser beams, and the inscription temperature. Different systems were studied: azopolymers or amorphous molecular azomaterials where the azo is covalently bonded as a side-chain or is part of the main chain, ${ }^{17}$, ${ }^{21-22}$ photopassive polymers doped with azo derivatives, ${ }^{23}$ and supramolecular complexes in which azo molecules are bonded in a non-covalent fashion to a photopassive polymer through hydrogen, ${ }^{24}$ halogen ${ }^{25}$ or ionic bonding ${ }^{26-27}$. While these systems provide useful insight on the SRG process, they do not allow to clearly disentangle the respective influences of $\mathrm{T}_{\mathrm{g}}$ and azo content. Indeed, changing the azo content usually affects the $\mathrm{T}_{\mathrm{g}}$ and the molecular weight of the system and, in the case of azopolymers and supramolecular polymer complexes, the entanglement density and chain rigidity. Similarly, tuning the $\mathrm{T}_{\mathrm{g}}$ of azomaterials while keeping the azo content fixed necessitates using different host polymer matrices or synthesizing different azopolymers, which inevitably involves variation of the abovementioned interdependent characteristics and blurs the source of the SRG performance and inscription efficiency. Some trends are already known concerning the effects of azo content and temperature, e.g. using a higher azo content increases diffraction efficiency (DE) while a higher inscription temperature relative to $\mathrm{T}_{\mathrm{g}}$ decreases $\mathrm{DE}$, inscription kinetics and stability of SRGs due to more important thermal relaxation. ${ }^{21-22,28-32}$ Nevertheless, probing the influence of the $T_{g}$ and azo content parameters individually remains a major challenge.

Lebel and coworkers have recently synthesized a molecular glass functionalized with the azo Dispersed Red 1 (DR1), gDR1, and demonstrated that it is an efficient SRG (see Figure $4 \mathrm{~b}$ in reference 33 for a representative atomic force microscopy image) and nanoscale surface patterning material. ${ }^{33-35}$ Such azo-containing molecular glasses, which are small organic molecules that easily form a long-lived amorphous phase (avoiding the risk of azo crystallization), open a new avenue to study independently the impact of $\mathrm{T}_{\mathrm{g}}$ and azo content on the photoactivity of azomaterials such as their photoinduced orientation/birefringence and their photomobility. In particular, by blending photoactive gDRı with a library of its photopassive structural analogues, we are able to tune the $\mathrm{T}_{\mathrm{g}}$ of the resulting photoactive blends from below to well above room temperature while keeping the azo content constant. Our approach innovates by presenting several advantages over other systems used to study the temperature dependence of SRG inscription. First, using molecular glasses for the photoactive and passive components eliminates dispersity issues and large differences in molecular weight (and entanglement density in the case of polymers) between the compared materials. ${ }^{36}$ Second, it allows tuning the relative inscription temperature more easily than by modifying the experimental temperature, which requires adding a low pressure chamber on the setup to avoid air turbulence at high temperatures $^{29}$ or even water vapor condensation at low temperatures. Third, the same azo chromophore is used in all the experiments, ensuring extremely similar optical properties and photoactivity for all blends, by opposition to systems comparing azo substituents that differ in size and/or electronic properties. ${ }^{37-38}$ Finally, the structural similitude between gDRı and all the photopassive molecular glasses favors similar intermolecular interactions and molecularlevel miscibility which are difficult to reproduce with polymer/azopolymer blends and with polymer/azo blends or complexes.

This systematic approach was used to prepare two series of seven amorphous blends containing 10 or $40 \mathrm{~mol} \%$ of gDR1, respectively, and presenting $\mathrm{T}_{\mathrm{g}}$ 's from 19 to $88^{\circ} \mathrm{C}$. Our results reveal that a $\mathrm{T}_{\mathrm{g}} 25-40{ }^{\circ} \mathrm{C}$ above ambient temperature is optimal to produce SRGs with fastest inscription kinetics and with highest maximal and residual DE. When $T_{g}$ is below the optimal value, thermal relaxation competes with photoinduced motion and leads to low DE. When $T_{g}$ is higher than the optimal range, DE values plateau for the $40 \mathrm{~mol} \%$ blends and decrease for the $10 \mathrm{~mol} \%$ blends. Time-resolved polarized infrared spectroscopy ${ }^{39}$ revealed that this optimal $\mathrm{T}_{\mathrm{g}}$ range results from a compromise between i) the photo-orientation capability of the chromophore, which enables higher saturated DE and is optimal when $\mathrm{T}_{\mathrm{g}}$ is $50{ }^{\circ} \mathrm{C}$ above ambient temperature, and ii) the higher resistance to motion of high- $\mathrm{T}_{\mathrm{g}}$ matrices, as revealed by the residual orientation values, that limits the SRG inscription kinetics of the system and is especially important at low azo content. Our strategy of blending photoactive and photopassive glasses enabled reaching clear conclusions on the effects of $\mathrm{T}_{\mathrm{g}}$ and azo content on the photoactivity of azomaterials that are essential to optimize the SRG inscription process that, to our knowledge, would not have been possible using other approaches.

\section{EXPERIMENTAL SECTION}

Materials. Compounds gDR1 and g-25 to g94 were synthesized according to literature procedures..$^{40-42}$ Blends with 10 and $40 \mathrm{~mol} \%$ (molar percentages) of gDR 1 with compounds g-25 to g94 $\left(\mathrm{B}_{10} \%_{\mathrm{Tg}}\right.$ and $\left.\mathrm{B} 40 \%_{\mathrm{Tg}}\right)$ were prepared by mixing the appropriate volume of their respective stock solutions in $\mathrm{CH}_{2} \mathrm{Cl}_{2}$.

Characterization. For differential scanning calorimetry (DSC) analyses, droplets of the blend solutions were directly deposited in DSC pans to generate approx. $2.5 \mathrm{mg}$ samples before letting the solvent evaporate under a fume hood for 3-4 $\mathrm{h}$ and then under vacuum for $24 \mathrm{~h}$ before closing the pans with their lid. DSC measurements were conducted with a PerkinElmer DSC 8500 calorimeter, calibrated with indium, using a heating rate of $10^{\circ} \mathrm{C} / \mathrm{min}$. The $\mathrm{T}_{\mathrm{g}}$ 's were determined, after an initial cycle of heating and cooling at $10^{\circ} \mathrm{C} / \mathrm{min}$, as the average half-height of the heat capacity jump in the second and third heating scans. UV-visible spectra of samples spin-coated on clean glass substrates were recorded with an Ocean Optics USB20oo+ spectrophotometer and a DH-mini light source. The minimal cis content under irradiation was estimated as the ratio of absorbance of the $\pi-\pi^{*}$ band (at $480 \mathrm{~nm}$ ) of the films after $90 \mathrm{~s}$ of illumination with a non-polarized $520 \mathrm{~nm}(35$ $\mathrm{mW} / \mathrm{cm}^{2}$ ) LED light source (Prizmatix FC5-LED) to the initial absorbance of the band. The thermal relaxation halflife time of the cis isomer was determined by recording the absorbance at $480 \mathrm{~nm}$ during $300 \mathrm{~s}$ after switching off the 
LED source and fitting the data following the method of Barrett et al. ${ }^{43}$ which consists in plotting $\ln \left(\mathrm{A}_{\infty}-\mathrm{A}_{\mathrm{t}}\right)$ as a function of time, where $A_{t}$ and $A_{\infty}$ are the absorbance at time $t$ and after relaxation, respectively.

Polarization modulation infrared structural absorption spectroscopy (PM-IRSAS) was used to measure photo-orientation of the DR1 moiety. This technique enables the simultaneous recording of transmission IR spectra polarized parallel (p) and perpendicular (s) to the laser polarization, in addition to their dichroic difference, and therefore provides time-resolved information about the photoinduced orientation in situ during the photo-orientation process. ${ }^{39}$ Spectra with a $4 \mathrm{~cm}^{-1}$ resolution were measured using a Bruker Optics Vertex 70 Fourier transform IR spectrometer coupled to a home-built setup ${ }^{25}$ that includes a KRS- 5 linear polarizer (Optometrics), a photoelastic modulator (PEM-9o type II/ZS50, Hinds Instruments) to switch the polarization of the IR beam from parallel to perpendicular at $100 \mathrm{kHz}$, and a liquid nitrogen-cooled photovoltaic mercury-cadmium-telluride (MCT) detector (Kolmar Technologies). A lock-in amplifier (Stanford Research Systems SR830) with a $30 \mu$ s time constant and electronic filters (Frequency Devices 9oTP/9oIPB) were used to process the experimental signal and record simultaneously the parallel $\left(A_{p}\right)$ and perpendicular $\left(A_{s}\right)$ polarized IR spectra. The photo-orientation was induced by a $488 \mathrm{~nm}$ diode laser (JDSU FCD488-020) with a vertically-polarized output expanded to $7 \mathrm{~mm}$ (Thorlabs BE1oM-A) to overfill the crosssection area of the IR probe beam. The resulting 18 $\mathrm{mW} / \mathrm{cm}^{2}$ beam was incident on the sample at an angle of $20^{\circ}$ with respect to IR probe. The orientation parameter, $<\mathrm{P}_{2}>$, was calculated as $<\mathrm{P}_{2}>=\mathrm{A}_{\mathrm{p}}-\mathrm{A}_{\mathrm{s}} /\left(\mathrm{A}_{\mathrm{p}}+2 \mathrm{~A}_{\mathrm{s}}\right)$.

SRG inscription. To write the SRGs, a Lloyd's mirror interferometer was used to produce the interference pattern from a frequency-doubled diode pumped Nd-YVO 4 laser source operating at $532 \mathrm{~nm}$ (Coherent Verdi V5), having an approximate irradiance of $230 \mathrm{~mW} / \mathrm{cm}^{2}$. The beam passed through a spatial filter, was collimated and then was made circularly polarized with the help of a quarter-wave plate, so that two contra-rotating interfering beams were impinging the sample. This configuration yields an interference pattern on the sample surface with rotating linear polarization orientation and permits maximum molecular orientation. ${ }^{44}$ The first-order diffraction efficiency of a non-resonant beam, an in situ figure of merit of the efficiency of SRG formation (written at a constant $600 \mathrm{~nm}$ pitch for all SRGs in this work), was measured by aligning a Thorlabs low-power diode laser (405 $\mathrm{nm}$ ) beam in the middle of the half-circle laser interference pattern. The probe laser was initially chopped with a mechanical chopper and the first order diffracted signal was attenuated with neutral density filters before being incident on a silicon photodiode. The photodiode signal was then measured with a lock-in amplifier (Stanford Research Systems SR830) and recorded on a computer. The diffraction efficiency DE was calculated by dividing the first order diffracted signal by the zeroth transmitted order through the sample.

\section{RESULTS AND DISCUSSION}

Thermal and optical properties. The structures of the photoactive azo glass (gDR1) and photopassive compounds (labeled as $\mathrm{gT}_{\mathrm{g}}$, where $T_{g}$ stands for the glass transition temperature of the photopassive glass) are shown in Scheme 1. The photoisomerization between the trans and cis isomers of the DR1 moiety is also illustrated. The headgroup (X), the linkers ( $\mathrm{R}$ and $\mathrm{R}$ ') on their 1,3,5-triazine core and their ancillary groups (Ar) are listed in the Table 1 along with their respective glass transition temperatures $\left(\mathrm{T}_{\mathrm{g}}\right)$. These seven photopassive molecular glasses were chosen for their high resistance to crystallization, ${ }^{42}$ for their similar chemical structure to $\mathrm{gDR} 1$, and for their broad range of $\mathrm{T}_{\mathrm{g}}$ (between -25 and $94{ }^{\circ} \mathrm{C}$ ) that enable preparing photoactive amorphous miscible blends with a $\mathrm{T}_{\mathrm{g}}$ from below to well above ambient temperature.

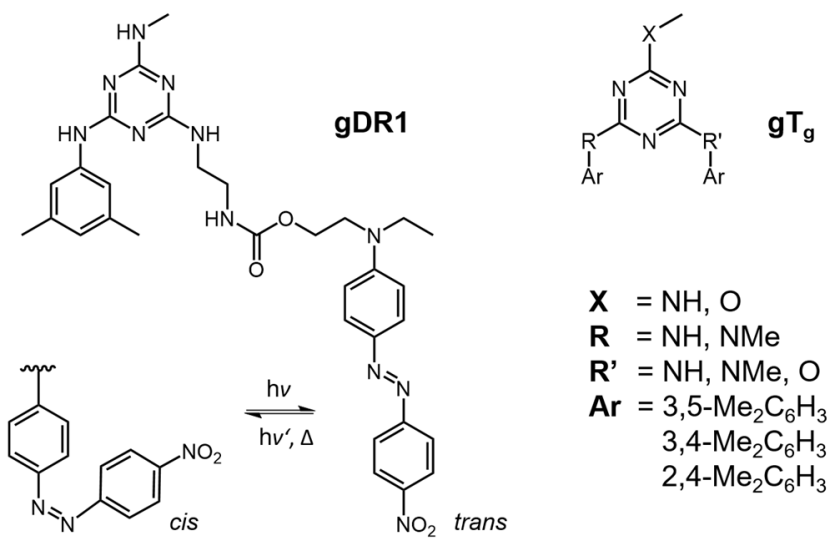

Scheme 1. Molecular structures of the photoactive (gDR1) and photopassive $\left(\mathrm{gT}_{\mathrm{g}}\right)$ molecular glasses used to prepare the photoactive blends under study.

Table 1. Variable substituents and glass transition temperatures $\left(\mathrm{T}_{\mathrm{g}}\right)$ of the photopassive $\left(\mathrm{g} \mathrm{T}_{\mathrm{g}}\right.$ ) and photoactive (gDR1) molecular glasses used to prepare the photoactive blends under study.

\begin{tabular}{c|cccc:c}
\hline $\mathbf{g T}_{\mathbf{g}}$ & $\mathbf{X}$ & $\mathbf{R}$ & $\mathbf{R}^{\prime}$ & $\mathbf{A r}$ & $\mathbf{T}_{\mathbf{g}}\left( \pm \mathbf{1}{ }^{\circ} \mathbf{C}\right)$ \\
\hline $\mathbf{g 9 4}$ & $\mathrm{NH}$ & $\mathrm{NH}$ & $\mathrm{NH}$ & $3,5-\mathrm{Me}_{2} \mathrm{C}_{6} \mathrm{H}_{3}$ & 94 \\
\hline $\mathbf{g 7 0}$ & $\mathrm{NH}$ & $\mathrm{NH}$ & $\mathrm{NH}$ & $3,4-\mathrm{Me}_{2} \mathrm{C}_{6} \mathrm{H}_{3}$ & 70 \\
$\mathbf{g} 54$ & $\mathrm{NH}$ & $\mathrm{NH}$ & $\mathrm{NH}$ & $\mathbf{2 , 4}-\mathrm{Me}_{2} \mathrm{C}_{6} \mathrm{H}_{3}$ & 54 \\
$\mathbf{g 3 7}$ & $\mathrm{O}$ & $\mathrm{NH}$ & $\mathrm{O}$ & $3,5-\mathrm{Me}_{2} \mathrm{C}_{6} \mathrm{H}_{3}$ & 37 \\
\hline g21 & $\mathrm{NH}$ & $\mathrm{NMe}$ & $\mathrm{NMe}$ & $3,5-\mathrm{Me}_{2} \mathrm{C}_{6} \mathrm{H}_{3}$ & $\mathbf{2 1}$ \\
\hline $\mathbf{g 8}$ & $\mathrm{O}$ & $\mathrm{NMe}$ & $\mathrm{O}$ & $3,5-\mathrm{Me}_{2} \mathrm{C}_{6} \mathrm{H}_{3}$ & 8 \\
\hline $\mathbf{g - 2 5}$ & $\mathrm{O}$ & $\mathrm{NMe}$ & $\mathrm{NMe}$ & $3,5-\mathrm{Me}_{2} \mathrm{C}_{6} \mathrm{H}_{3}$ & -25 \\
\hline gDR1 & - & - & - & - & 71 \\
\hline
\end{tabular}

Two series of blends were prepared with 10 or $40 \mathrm{~mol} \%$ of gDR1 (noted $\mathrm{B}_{10} \%$ and $\mathrm{B}_{4} \mathrm{O} \%$, respectively). The $\mathrm{T}_{\mathrm{g}}$ of these blends, determined using DSC with a scanning rate of $10^{\circ} \mathrm{C} / \mathrm{min}$, are shown as a function of the $\mathrm{T}_{\mathrm{g}}$ of the photopassive matrix in Figure 1 (also listed in Table $\mathrm{S}_{1}$ in Supporting Information (SI)). The $\mathrm{T}_{\mathrm{g}}$ of the blends increases smoothly with that of the photopassive glass and varies 
with blend composition. The $\mathrm{T}_{\mathrm{g}}$ of the $\mathrm{B} 4 \mathrm{O} \%$ series blends span from 37 to $81{ }^{\circ} \mathrm{C}$ (labeled as $\mathrm{B}_{40} \%_{37}$ to $\mathrm{B}_{40} \% \%_{81}$ ). Since the $\mathrm{B} 10 \%$ blends contain a low fraction of azo, this series allows getting closer to the $\mathrm{T}_{\mathrm{g}}$ of the pure matrices, thus extending the accessible temperature range from 19 to 88 ${ }^{\circ} \mathrm{C}\left(\mathrm{B} 10 \%{ }_{19}\right.$ to $\left.\mathrm{B} 10 \%{ }_{88}\right)$. No crystallization (or melting) was observed in any of the DSC scans, confirming the completely amorphous state of the resulting blends. Furthermore, the presence of a single glass transition with a similar width $\left(15-20{ }^{\circ} \mathrm{C}\right)$ as the pure compounds in the DSC scans of all blends indicates that no phase separation occurs between the photoactive and photopassive molecular glasses, thus ruling out the problems related to dye aggregation.

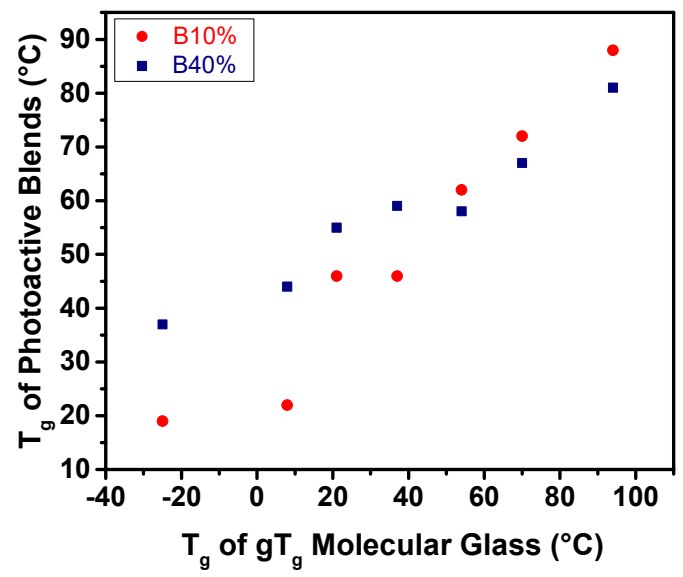

Figure 1. Evolution of $\mathrm{T}_{\mathrm{g}}\left( \pm 1^{\circ} \mathrm{C}\right)$ of the photoactive $\mathrm{B} 10 \%$ and $\mathrm{B} 40 \%$ blends as a function of the $\mathrm{T}_{\mathrm{g}}\left( \pm 1^{\circ} \mathrm{C}\right)$ of the photopassive compounds $\left(\mathrm{gT}_{\mathrm{g}}\right)$.

Figure $2 \mathrm{~A}$ shows the $\mathrm{UV}$-visible spectra of spin-coated thin films of gDR1 and of the $\mathrm{B} 10 \%{ }_{19}, \mathrm{~B} 10 \%{ }_{88}$ and $\mathrm{B}_{40} \%_{58}$ blends. The spectra of the blends are all superimposed, leading to the conclusion that their $\mathrm{T}_{\mathrm{g}}$ and azo content do not influence their absorption properties, at least in the studied ranges, and demonstrating the advantages of our blending strategy to ease the comparison between samples. The wavelength of maximal absorbance of the $\pi-\pi^{*}$ band is slightly red-shifted for the blends $(\sim 487 \mathrm{~nm})$ compared to pure gDR $(\sim 480 \mathrm{~nm})$ and its width is smaller for the blends, two indications showing that the DRı chromophores are well isolated from each other in the blends and avoid forming aggregated stacks that lead to excitonic coupling as observed in the spectrum of pure gDR $1 .{ }^{45}$ As a consequence, these blends enable studying more specifically the impact of $\mathrm{T}_{\mathrm{g}}$ and azo content on photoactivity (SRG inscription and photoinduced orientation) since the photoisomerization of the DR1 moiety should not be affected by different degrees of coupling between adjacent chromophores.

Samples were irradiated with an unpolarized $520 \mathrm{~nm}$ LED source, followed by thermal relaxation, in order to study the influence of $\mathrm{T}_{\mathrm{g}}$ on the minimal cis content under photostationary state and on the cis half-life time. The spectrum of $\mathrm{B}_{40} \%_{58}$ under irradiation is shown as a representative example in Figure $2 \mathrm{~A}$. The decrease of absorbance of the $\pi-\pi^{*}$ band under illumination is attributed to
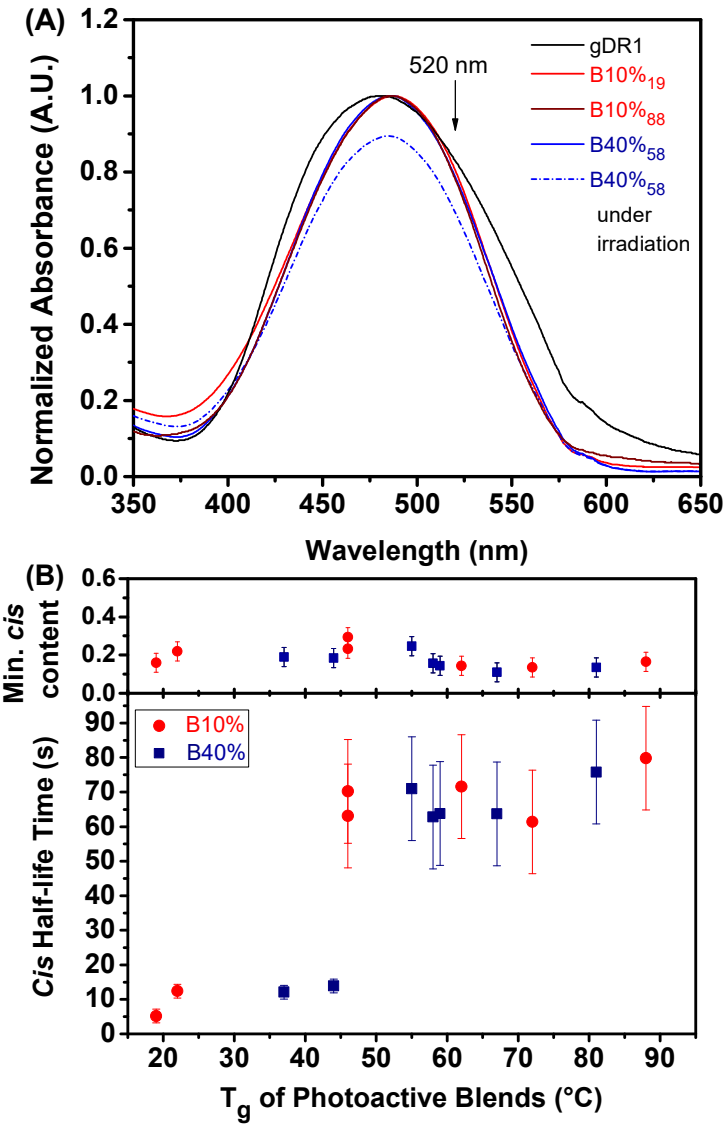

Figure 2. A) UV-visible spectra of pure $\mathbf{g D R} \mathbf{1}, \mathrm{B} 10 \%$ blends with g94 and g-25 $\left(\mathrm{B}_{10} \%_{88}, \mathrm{~B}_{10} \%_{19}\right)$ and $\mathrm{B}_{40} \%$ with g54 $\left(\mathrm{B} 40 \%_{58}\right)$. The spectrum of $\mathrm{B} 40 \%_{58}$ upon irradiation at $520 \mathrm{~nm}$ is also shown. B) Top panel: minimal cis content of the azo moiety of gDRı blends as a function of their $\mathrm{T}_{\mathrm{g}}$. Bottom panel: cis isomer half-life time of the azo moiety of gDRı blends as a function of the $\mathrm{T}_{\mathrm{g}}$ photoactive blends.

the photoinduced formation of cis isomers and is used to estimate the minimal cis content under irradiation. When the light is turned off, the absorbance recovers gradually and allows estimating the cis isomer half-life time. These values are plotted as a function of the $\mathrm{T}_{\mathrm{g}}$ of the blends in Figure $2 \mathrm{~B}$. The minimal cis content under illumination (upper panel) does not vary significantly with $\mathrm{T}_{\mathrm{g}}$ or azo content, with an average of $0.15 \pm 0.05$ for both $\mathrm{B} 10 \%$ and $\mathrm{B} 40 \%$ series. This relatively small cis isomer content is explained by the fact that the $520 \mathrm{~nm}$ irradiation excites both the trans $\pi-\pi^{*}$ and the cis $\mathrm{n}-\pi^{*}$ bands and thus leads to rapid trans-cis-trans isomerization cycles, which is required for efficient SRG inscription. ${ }^{46}$ On the other hand, the cis half-life time (lower panel) does increase with the $\mathrm{T}_{\mathrm{g}}$ of the photoactive blends for both series, starting around $5 \mathrm{~s}$ for the lowest $\mathrm{T}_{\mathrm{g}}$ blends and increasing suddenly to reach a plateau on the order of $70 \mathrm{~s}$ when $\mathrm{T}_{\mathrm{g}}$ is around $50{ }^{\circ} \mathrm{C}$ or higher. This increase in cis half-life time reflects the difference between a viscous and a glassy state, in which the thermal cis-trans isomerization rate is presumably slowed down because less free volume is available in the material for the transition to occur. Interestingly, this result is in contradiction with the larger rate constant reported by Nakano et al. ${ }^{21}$ for high $T_{g}$ amorphous films $\left(T_{g}=\right.$ 
$97^{\circ} \mathrm{C}, \mathrm{k}=0.020 \mathrm{~min}^{-1}$ ) of azo-containing molecular glasses compared to lower $\mathrm{T}_{\mathrm{g}}$ ones $\left(\mathrm{T}_{\mathrm{g}}=27{ }^{\circ} \mathrm{C}, \mathrm{k}=0.006 \mathrm{~min}^{-1}\right)$ when measured at $30{ }^{\circ} \mathrm{C}$. In our case, the capability of the matrix to hydrogen $(\mathrm{H})$-bond with the cis isomer may explain the longer cis half-life time. Indeed, the long cis lifetimes are observed for the high- $\mathrm{T}_{\mathrm{g}}$ blends where the matrix glass contains at least one $\mathrm{H}$-bond donating group while the short lifetimes are observed for the low- $\mathrm{T}_{\mathrm{g}}$ blends where the matrix does not contain H-bond donating groups. The fact that the minimal cis content under irradiation is similar for all blends indicates that the cis isomers cannot accumulate in spite of their longer thermal relaxation lifetime and may be explained by hydrogen bonding of the matrix with the trans isomer of DR1.

Surface relief grating formation. Figure 3 shows the first order diffraction efficiency (DE) as a function of writing time during the inscription of SRGs at $532 \mathrm{~nm}$ (close to the $520 \mathrm{~nm}$ irradiation used in the UV-visible experiments) for the $\mathrm{B}_{40} \%$ (Figure $3 \mathrm{~A}$ ) and $\mathrm{B} 10 \%$ (Figure $3 \mathrm{~B}$ ) series. They will be referred to as the SRG inscription curves. Besides the curve shape per se, various information can be extracted from these inscription curves: 1 ) the DE reached after 100 or 1000 s of illumination, 2) the initial rate of SRG inscription, and 3) the residual DE after the laser is turned off. All of them will be discussed in relation to the $\mathrm{T}_{\mathrm{g}}$ of the blends and the azo content.

As shown in Figure $3 \mathrm{~A}$, the shape of the SRG inscription curves is similar for all the B40\% blends. The DE increases rapidly during the first $100 \mathrm{~s}$ before slowing down and reaching a pseudo-plateau. The filled blue squares in Figure 4 represent the DE reached after $1000 \mathrm{~s}$ of irradiation ( $\mathrm{DE}_{1000}$, which is or is close to the maximal DE reached during the inscription) as a function of $\mathrm{T}_{\mathrm{g}}$ for the $\mathrm{B}_{4} \mathrm{0} \%$ series. The $\mathrm{DE}_{1000}$ increases with $\mathrm{T}_{\mathrm{g}}$, starting around $2.5 \%$ for the lowest $\mathrm{T}_{\mathrm{g}}$ sample $\mathrm{B}_{40} \%_{37}$ and reaching a plateau of $\sim 18 \%$ for blends with a $\mathrm{T}_{\mathrm{g}}$ higher than $6 \mathrm{o}^{\circ} \mathrm{C}$. In contrast with the $\mathrm{B} 40 \%$ series, the SRG inscription curves of the $\mathrm{B} 10 \%$ samples do not all present the same shape (Figure $3 \mathrm{~B}$ ). Only the two $\mathrm{B}_{10} \%_{46}$ samples have inscription curves similar to those of the $\mathrm{B}_{40} \%$ series and reach high $\mathrm{DE}_{1000}$, while the inscription curves of the other $\mathrm{B} 10 \%$ samples with both lower and higher $\mathrm{T}_{\mathrm{g}}$ are too low to be clearly visible in Figure $3 \mathrm{~B}$. A close-up provided in Figure $\mathrm{S}_{1}$ of the SI shows that an induction period precedes a slow SRG growth for high $\mathrm{T}_{\mathrm{g}}$ blends. In contrast, for lower $\mathrm{T}_{\mathrm{g}}$ blends, transient and partially transient (phase and birefringence, respectively) gratings build up rapidly but they are not followed by the formation of a permanent topological grating; instead, a decrease of DE is observed after a few seconds of irradiation and is followed by a low DE value plateau. A complete erasure (loss of DE) occurs after stopping illumination, confirming that only a transient grating was present. This shape was already reported for experiments conducted at temperatures less than $20{ }^{\circ} \mathrm{C}$ below the $\mathrm{T}_{\mathrm{g}}$ of azopolymers (pDR1M and pMEA) ${ }^{29}$ and for low $\mathrm{T}_{\mathrm{g}}\left(15\right.$ to $40{ }^{\circ} \mathrm{C}$ ) polyazosiloxane $^{30}$ and has been attributed to the more important relative contribution of thermal relaxation compared to photoinduced motion.
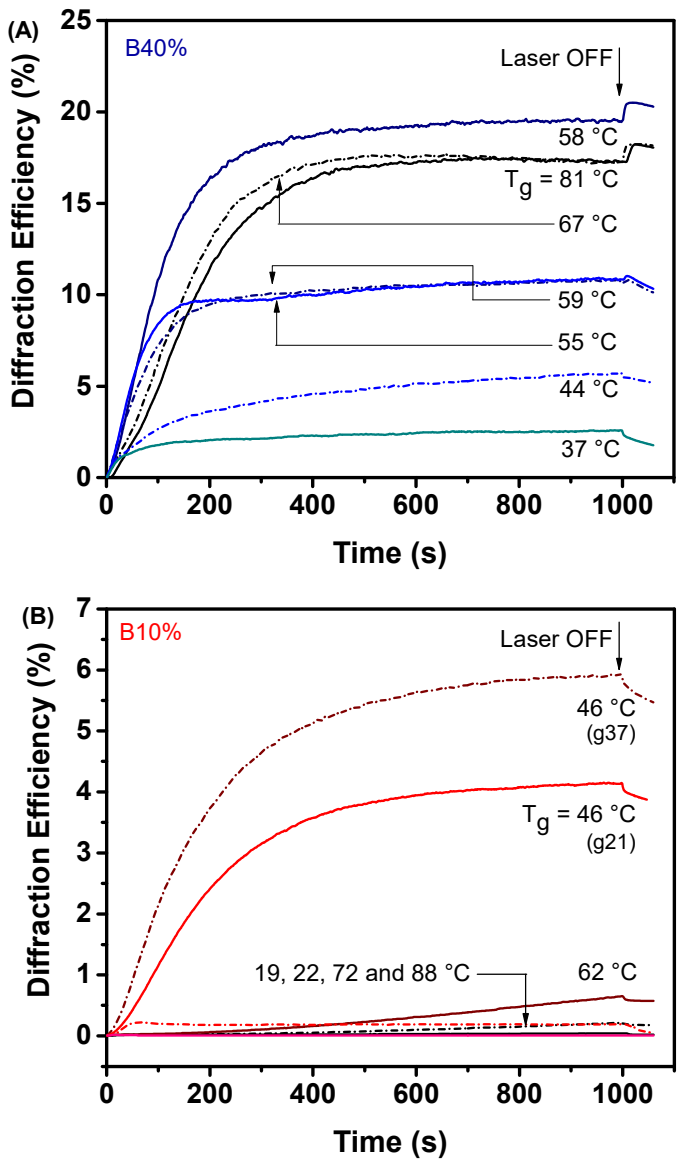

Figure 3. Diffraction efficiency (DE) as a function of time during the inscription of surface relief gratings for the $\mathrm{B} 40 \%$ (A) and $\mathrm{B}_{10} \%(\mathrm{~B})$ blends. Glass transition temperatures $\left(\mathrm{T}_{\mathrm{g}}\right)$ of the photoactive blends are indicated for each inscription curve. Since two samples from the $\mathrm{B} 10 \%$ series have the same $\mathrm{T}_{\mathrm{g}}$, the photopassive glass used as their matrix is indicated in parenthesis below the $\mathrm{T}_{\mathrm{g}}$ of the blends. An enlargement of the low $\mathrm{DE}$ inscription curves for the B10\% samples with $\mathrm{T}_{\mathrm{g}}$ 's below 46 ${ }^{\circ} \mathrm{C}$ and above $62{ }^{\circ} \mathrm{C}$ is shown in Figure $\mathrm{S}_{1}$ in SI.

The $\mathrm{DE}_{1000}$ for the $\mathrm{B} 10 \%$ samples are shown as filled red circles in Figure 4. The DE is essentially zero when $T_{g}$ is below the inscription (ambient) temperature ( $\sim 0.01 \%$ for $\mathrm{B} 10 \%{ }_{19}$ ) and is extremely low when $\mathrm{T}_{\mathrm{g}}$ is close to the inscription temperature $\left(0.18 \pm 0.01 \%\right.$ for $\left.\mathrm{B} 10 \%{ }_{22}\right)$. Such low DE values were reported for SRGs inscribed on low $\mathrm{T}_{\mathrm{g}}\left(27^{\circ} \mathrm{C}\right)$ azo molecular glasses. ${ }^{21}$ The $\mathrm{DE}$ then rapidly increases to reach a maximal value of $\sim 5 \%$ at a $\mathrm{T}_{\mathrm{g}}$ of $46^{\circ} \mathrm{C}$ which, by opposition to the $\mathrm{B} 40 \%$ series, is not followed by a plateau at high $\mathrm{T}_{\mathrm{g}}$. Instead, an important decrease of DE is observed with further increase in $\mathrm{T}_{\mathrm{g}}$, down to approximately $0.04 \%$ for the highest $\mathrm{T}_{\mathrm{g}}$ sample $(\mathrm{B} 10 \% 88)$. Such low DE values were also reported for SRGs prepared with high- $\mathrm{T}_{\mathrm{g}}$ azopolymer complexes when the azo content was particularly low. ${ }^{47}$ Furthermore, the azo content has an important influence on DE when comparing samples with a similar $\mathrm{T}_{\mathrm{g}}$, especially for high $\mathrm{T}_{\mathrm{g}}$. In particular, the $\mathrm{B} 10 \%_{72}$ sample presents a very low $\mathrm{DE}_{1000}$ of $0.21 \pm 0.02 \%$ while a much higher $\mathrm{DE}_{1000}$ of $17.4 \pm 0.5 \%$ is reached by $\mathrm{B}_{40} \%{ }_{67}$. In fact, an even larger $\mathrm{DE}_{1000}$ of around $30.0 \pm 0.7 \%$ is obtained under the same irradiation conditions for pure gDR1, which can be 
seen in this comparison as a $100 \mathrm{~mol} \%$ sample with a very similar $\mathrm{T}_{\mathrm{g}}$ of $71{ }^{\circ} \mathrm{C}$ (a representative inscription curve is provided in Figure $\mathrm{S}_{2}$ of the $\mathrm{SI}$ ).

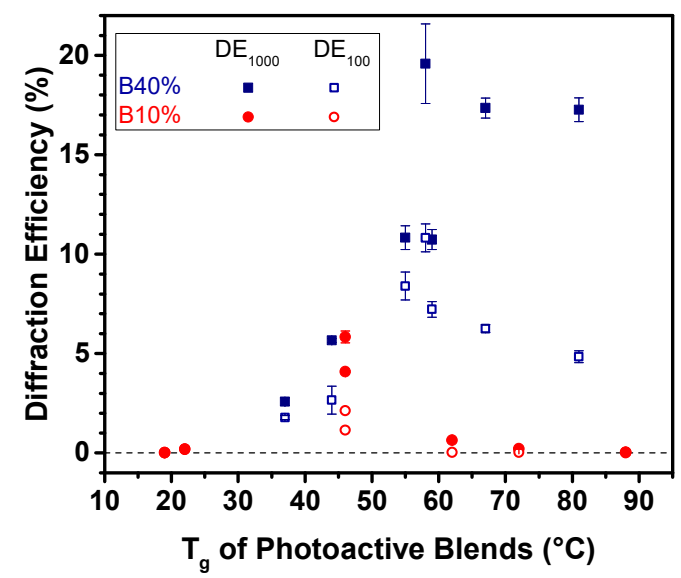

Figure 4. Diffraction efficiency at $1000 \mathrm{~s}$ (filled symbols) and $100 \mathrm{~s}$ (empty symbols) for the $\mathrm{B} 10 \%$ and $\mathrm{B} 40 \%$ blends as a function of their glass transition temperatures $\left(\mathrm{T}_{\mathrm{g}}\right)$.

Since the DR1 moiety possesses the same optical properties (vide supra) in both the $\mathrm{B} 10 \%$ and $\mathrm{B} 40 \%$ series, it is reasonable to think that a $\mathrm{DE}$ value plateauing around $5 \%$ could have been reached for the high- $\mathrm{T}_{\mathrm{g}} \mathrm{B10} \%$ samples $\left(\mathrm{B}_{10} \%_{62}, \mathrm{~B}_{10} \%_{72}\right.$ and $\left.\mathrm{B}_{10} \%_{88}\right)$ if the inscription time had been long enough. Indeed, the SRG inscription curves for these samples (better seen in Figure $\mathrm{S}_{1}$ ) do not show any sign of saturation after $1000 \mathrm{~s}$ of irradiation, in contrast with those of the $\mathrm{B} 40 \%$ samples and of the $\mathrm{B} 10 \%_{46}$ samples that reach a quasi-plateau in Figure $3 \mathrm{~A}$ and $3 \mathrm{~B}$, respectively. This kinetic limitation hypothesis is reinforced by the $\mathrm{DE}$ values recorded at $100 \mathrm{~s}\left(\mathrm{DE}_{100}\right)$, represented by empty symbols in Figure 4. For both series, a bell shape is observed with a maximum $\mathrm{DE}$ reached at intermediate $\mathrm{T}_{\mathrm{g}}$ 's, as was observed for the $\mathrm{B} 10 \%$ blends after $1000 \mathrm{~s}$. For the $\mathrm{B}_{40} \%$ series, the maximal $\mathrm{DE}_{100}$ occurs at the $\mathrm{T}_{\mathrm{g}}$, around 60 ${ }^{\circ} \mathrm{C}$, that corresponds to the onset of the $\mathrm{DE}_{100}$ plateau. The gap between $\mathrm{DE}_{1000}$ and $\mathrm{DE}_{100}$ increases above this $T_{\mathrm{g}}$, meaning that a longer time is needed to reach the plateau value for higher $\mathrm{T}_{\mathrm{g}}$ samples. A similar gap is also observed for pure gDR 1 , where the DE is $\sim 11 \%$ after 100 s compared to $\sim 30 \%$ after $1000 \mathrm{~s}$, which confirms this trend (see Figure $\mathrm{S}_{2}$ in SI). For the $\mathrm{B}_{10} \%$ samples with a $\mathrm{T}_{\mathrm{g}}$ close to the inscription temperature, there is no difference between $\mathrm{DE}_{1000}$ and $\mathrm{DE}_{100}$ because the maximal (very low) attainable $\mathrm{DE}$ is reached before $100 \mathrm{~s}$. This behavior is due to the viscous state of the material where any photoinduced motion is effectively compensated by the thermal relaxation. At intermediate $\mathrm{T}_{\mathrm{g}}$, the gap between $\mathrm{DE}_{100}$ and $\mathrm{DE}_{100}$ is larger, as observed for the $\mathrm{B} 40 \%$ samples with high $\mathrm{T}_{\mathrm{g}}$ for which the inscription rate is a limiting factor. This observation is consistent with the fact that the shape of the SRG inscription curves of the two intermediate $\mathrm{T}_{\mathrm{g}}$ samples is the same as for the $\mathrm{B} 4 \mathrm{o} \%$ samples - the inscription time was long enough to reach a plateau DE. However, in contrast to the high $\mathrm{T}_{\mathrm{g}} \mathrm{B} 40 \%$ samples, the gap between $\mathrm{DE}_{1000}$ and $\mathrm{DE}_{100}$ decreases for the highest $\mathrm{T}_{\mathrm{g}} \mathrm{B} 10 \%$ samples because their very slow inscription kinetics lead to very low $\mathrm{DE}$. To summarize, high- $\mathrm{T}_{\mathrm{g}}$ samples have the potential to reach higher maximal DE values, up to a plateau that depends on the azo content, but their inscription kinetics is increasingly hindered by the increasing viscosity of the matrix, in particular when the azo content is small.

These results suggest that an optimal $\mathrm{T}_{\mathrm{g}}$ value exists to optimize both the SRG inscription speed and maximal DE value and that this optimal $\mathrm{T}_{\mathrm{g}}$ depends on the azo content. For the $\mathrm{B} 40 \%$ series, Figures $3 \mathrm{~A}$ and 4 show that this optimal $\mathrm{T}_{\mathrm{g}}$ is around $60{ }^{\circ} \mathrm{C}$. For the $\mathrm{B10} \%$ series with a lower azo fraction, a $\mathrm{T}_{\mathrm{g}}$ around $45^{\circ} \mathrm{C}$ seems to be optimal to obtain rapidly a maximal DE value, but the fact that the B10 $\%_{46}$ samples (and those with higher $\mathrm{T}_{\mathrm{g}}$ ) have not reached a DE plateau after $1000 \mathrm{~s}$ of inscription suggests that the optimal $\mathrm{T}_{\mathrm{g}}$ would be somewhat lower for longer inscription times. The higher optimal $\mathrm{T}_{\mathrm{g}}$ for samples with a higher azo content can be rationalized by considering their larger number density of azo undergoing trans-cistrans photoisomerization cycles (by a factor of approximately 4 when comparing the $\mathrm{B} 40 \%$ and $\mathrm{B} 10 \%$ series since their fraction of cis isomers under irradiation similar in Figure $2 \mathrm{~B}$ ). Our previous work ${ }^{13}$ has shown that the molecular environment around the DR1 azos undergoing photoisomerization corresponds to an effective temperature much higher than the inscription temperature and even well above the $\mathrm{T}_{\mathrm{g}}$ of all the blends studied here. In contrast, the effective temperature of the matrix (or polymer backbone for a DR1-containing azopolymer) was not affected by irradiation, leaving the bulk $\mathrm{T}_{\mathrm{g}}$ of the sample unaffected by illumination and preventing viscous flow during SRG inscription. In this context, samples with a larger azo fraction are more capable of perturbing the matrix, either directly by applying more stress on the matrix or by creating a larger relative fraction of free volume that facilitates motion of the matrix by a structural relaxation process. Therefore, samples with a higher azo fraction can perturb matrices with a higher $\mathrm{T}_{\mathrm{g}}$, leading to the increase of the optimal $\mathrm{T}_{\mathrm{g}}$ from 45 to $60{ }^{\circ} \mathrm{C}$ between the $\mathrm{B} 10 \%$ and $\mathrm{B} 40 \%$ series. Since a higher $\mathrm{T}_{\mathrm{g}}$ better prevents isotropic viscous flow of the matrix under illumination (and under dark conditions after SRG writing), the shift of optimal $\mathrm{T}_{\mathrm{g}}$ to higher temperatures is accompanied by a higher maximal DE at the plateau for the azo-rich blends. In this context, it is interesting to note that pure gDR 1 and $\mathrm{pDR} 1 \mathrm{~A}$, one of the most commonly used azopolymer for SRG inscription, both reach maximal DE higher than any of the blends studied here. They possess $\mathrm{T}_{\mathrm{g}}$ values of $71^{\circ} \mathrm{C}$ and approximately 85 ${ }^{\circ} \mathrm{C}$ (for $\left.\mathrm{Mw}=5000 \mathrm{~g} / \mathrm{mol}\right),{ }^{13}$ respectively, above the optimal $\mathrm{T}_{\mathrm{g}}$ of the $\mathrm{B} 4 \mathrm{O} \%$ blends. Since the azo moiety occupies an increasingly larger fraction in the order of $\mathrm{B}_{10} \%<\mathrm{B} 40 \%<$ $\mathrm{gDR}_{1}<\mathrm{pDR}_{1} \mathrm{~A}$ (when considered as a repeat unit) and assuming that the optimal $\mathrm{T}_{\mathrm{g}}$ continues increasing beyond 40\% (not linearly since azo-azo interactions affect the photoisomerization efficiency), it can be speculated that the very strong potential for SRG inscription of $\mathrm{gDR} 1$ and pDR1A arises from their high azo content combined with a $\mathrm{T}_{\mathrm{g}}$ close to the optimal $\mathrm{T}_{\mathrm{g}}$ for DR1-containing azomaterials. 
The efficiency of the SRG inscription process can also be discussed in terms of the initial rate at which DE develops. Since the diffraction efficiency increases quasi linearly when the irradiation starts for the $\mathrm{B} 40 \%$ series, the initial rate can be estimated from the slope of the linear portion of the inscription curves between 10 and $20 \mathrm{~s}$. The analogous analysis cannot be done for the $\mathrm{B} 10 \%$ series since the shape of the seven SRG inscription curves is too different. ${ }^{48}$ The results in Figure $\mathrm{S}_{3} \mathrm{~A}$ show that the inscription rate (in $\% / s$ ) first increases with $\mathrm{T}_{\mathrm{g}}$, reaches a maximum twice as large as the initial value at $\mathrm{T}_{\mathrm{g}}$ 's between 55 and $60{ }^{\circ} \mathrm{C}$, and then decreases with further increase of $\mathrm{T}_{\mathrm{g}}$. The maximum of the bell corresponds well to the optimal $\mathrm{T}_{\mathrm{g}}$ value beyond which the maximal DE of $\sim 18 \%$ is achieved. This shape can be rationalized as following: with a low $\mathrm{T}_{\mathrm{g}}$, photoinduced mass transport is efficient but the rapid thermal relaxation of the matrix compromises the stability of the forming grating, which slows down the overall inscription efficiency and limits the maximum DE attainable. At an intermediate $T_{g}$ that depends on the azo fraction, an optimal balance is found between these two contributions. This trend from low to intermediate $\mathrm{T}_{\mathrm{g}}$ is analogous to the one reported by Veer et al. where the SRG inscription rate (and final height) decreased exponentially with increasing experimental temperature ${ }^{29}$ (a high temperature corresponding to a low $T_{g}$ in our case). Finally, when $T_{g}$ is above the optimal value, thermal relaxation of the matrix may become negligible but its high viscosity impedes photoinduced mass transport.

It is possible to discuss the inscription rate results from a more fundamental point of view by normalizing the initial slope of the SRG inscription curves by the $\mathrm{DE}_{1000}$ reached by their corresponding blends. Figure $\mathrm{S}_{3} \mathrm{~B}$ in $\mathrm{SI}$ indicates that the SRG inscription rate $\left(\right.$ in s$\left.^{-1}\right)$ decreases as $T_{g}$ increases, which quantitatively confirms the important role of matrix viscosity as discussed qualitatively above. These interpretations are also supported by our previous infrared spectroscopy results showing that under illumination, the molecular environment of the gDRı aminotriazine moiety is not modified even when the environment of the azo is highly perturbed by photoisomerization-induced free volume. A very high $\mathrm{T}_{\mathrm{g}}$ thus hinders the structural relaxation of the matrix needed to adapt to this photoinduced free volume.

In addition to the azo concentration and $\mathrm{T}_{\mathrm{g}}$, the intermolecular interactions present in the material environment also seem to influence the maximal DE. It can be observed in Figure 4 that samples $\mathrm{B}_{40} \%_{58}$ and $\mathrm{B}_{40} \mathrm{O} \%_{59}$ show very different saturated $D E$ values of $20 \pm 2 \%$ and $10.7 \pm 0.5$ $\%$, respectively, in spite of their almost identical $\mathrm{T}_{\mathrm{g}}$ and azo content. This difference could be due to the presence of three hydrogen $(\mathrm{H})$-bond donating groups in the headgroup and linkers of the g54 molecular glass composing the photopassive matrix for $\mathrm{B} 40 \%_{58}$, compared to only one in g37 which constitutes the photopassive matrix of $\mathrm{B} 40 \%{ }_{59}$. The $\mathrm{B}_{40} \%_{55}$ sample, which has a similar $\mathrm{T}_{\mathrm{g}}$ and whose matrix glass (g21) also contains only one $\mathrm{NH}$ group, also reaches a $\mathrm{DE}$ value of $\sim 11 \%$. Since we have shown that the presence of numerous $\mathrm{NH}$ groups, among others, impacts the thermal properties of molecular glasses, ${ }^{41-42} \mathrm{H}$-bonding could promote the matrix motion to adapt to the reorientation of the azo following its photoisomerization cycle, thus leading to higher achievable DE values and providing an additional approach to optimize SRG formation potential of photoactive azo blends.

When the laser is turned off at the end of the SRG inscription process (after $1000 \mathrm{~s}$ of illumination), either an increase or a decrease in DE can be observed in Figures 3 and $\mathrm{S}$. To compare quantitatively the temporal stability of the gratings, the residual diffraction efficiency was calculated as the percentage of the DE value recorded 6o s after ceasing the irradiation with respect to $\mathrm{DE}_{1000}$. This residual $D E$ value is an indicator of the relative importance of the transient and permanent gratings. ${ }^{49}$ When the laser is turned off, the transient gratings disappear and the residual DE will solely be due to the SRG. It is possible that a phase difference between the transient volume gratings and the surface relief grating could explain the decrease or increase in DE after laser irradiation is stopped, depending on whether the gratings diffract in phase or not, respectively. ${ }^{5 \circ}$ Figure 5 shows the complete absence of residual $\mathrm{DE}(\mathrm{o} \%)$ for the samples with a $\mathrm{T}_{\mathrm{g}}$ at or below the inscription temperature and its gradual increase up to $90 \%$ as $\mathrm{T}_{\mathrm{g}}$ increases toward the above-defined optimal values. The residual DE of B10\% samples decrease with a further increase in $\mathrm{T}_{\mathrm{g}}$ beyond their optimal $\mathrm{T}_{\mathrm{g}}$, down to $\sim 45 \%$ for $\mathrm{B} 10 \%{ }_{88}$. Since these high- $\mathrm{T}_{\mathrm{g}}$ blends did not reach a saturated DE plateau in Figure 4 because the slow motion of the matrix reduced the inscription kinetics of the topological grating, this decrease in residual DE can be explained by the lower contribution of the permanent topological grating relative to the transient gratings.

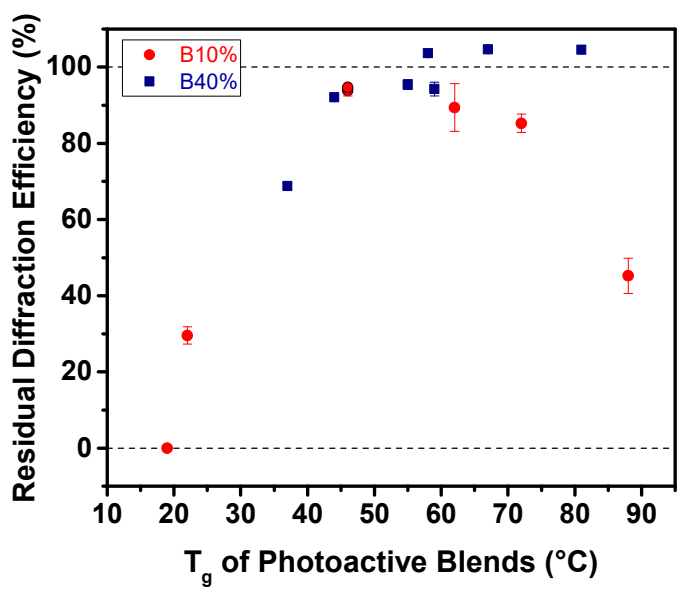

Figure 5. Residual diffraction efficiency of $\mathrm{B} 10 \%$ and $\mathrm{B} 40 \%$ as a function of their glass transition temperatures $\left(\mathrm{T}_{\mathrm{g}}\right)$.

Interestingly, three samples $\left(\mathrm{B}_{40} \%_{81}, \mathrm{~B}_{40} \%_{67}\right.$ and $\mathrm{B} 40 \%_{58}$ ) show an increase in DE when the laser is turned off with residual DE of $104-105 \%$. Two common characteristics of these samples are that their $\mathrm{T}_{\mathrm{g}}$ is close to or beyond the optimal $\mathrm{T}_{\mathrm{g}}$ (in this case $6 \mathrm{o}^{\circ} \mathrm{C}$ ) and that their azo content is high enough to reach the DE saturation plateau within the timescale of the inscription experiment. Pure gDR 1 also shares these characteristics and shows a residual 
DE of approximately $135 \%$, the highest value recorded. These observations could be tentatively explained by considering that a high enough orientation level must be achieved in order to promote further alignment of DR1 units or an additional directional motion of the matrix when the irradiation is stopped. As will be shown below, high global orientation level and stability can only be achieved with high azo content and high $\mathrm{T}_{\mathrm{g}}$. Previous studies of SRG inscription and photoinduced birefringence on other azomaterials support this suggestion: the amplitude of the DE increase after the laser is turned off decreased at higher experimental temperatures (analogous to a lower $\mathrm{T}_{\mathrm{g}}$ here) for a DRı containing copolymer; ${ }^{28}$ lower values of persistent DE were found for SRGs inscribed on films thinner than $50 \mathrm{~nm}$, which are known to show lower $\mathrm{T}_{\mathrm{g}}$ and higher mobility; ${ }^{49}$ liquid-crystalline block copolymers, when heated into their smectic phase upon and after irradiation, show an increasing birefringence under dark conditions after irradiation ${ }^{51}$ and supramolecular bisazopolymers behaved similarly only when their doping fraction was higher than $0.5 .^{52}$ Another possible explanation for these observations could be the influence of inscription temperature or sample $T_{g}$ on the phase difference between the transient and surface relief gratings created during the inscription process. ${ }^{53}$

Photoinduced orientation. In an attempt to link the observations made about the macroscopic mass transport with the molecular aspects of SRG inscription, PM-IRSAS measurements were conducted to track the photo-orientation of the azo moiety of gDRı upon illumination. A linearly polarized laser $\left(488 \mathrm{~nm}, 18 \mathrm{~mW} / \mathrm{cm}^{2}\right)$ was used with the goal of approaching the irradiation conditions during SRG inscription, where the contra-rotating interfering beams produce linearly polarized light. Polarized $\left(A_{p}\right.$ and $\left.\mathrm{A}_{\mathrm{s}}\right)$ and dichroic difference $(\Delta \mathrm{A})$ spectra for the $\mathrm{B}_{40} \%_{67}$ and $\mathrm{B}_{40} \%_{37}$ blends are shown in Figure $\mathrm{S}_{4}$ in SI. The $1104 \mathrm{~cm}^{-1}$ band chosen to quantify the orientation is due to an azobenzene aromatic ring deformation. ${ }^{13}$ The $\left\langle\mathrm{P}_{2}\right\rangle$ values calculated using this band are representative of the orientation of the whole chromophore because its transition dipole moment is parallel to the main axis of the DR1 moiety. Figure $\mathrm{S}_{5}$ in SI shows examples of the evolution of the photo-orientation as a function of time for samples $\mathrm{B}_{40} \%_{37}$ and $\mathrm{B}_{40} \%_{67}$. The initial $<\mathrm{P}_{2}>$ value is almost $\mathrm{o}$, which confirms a random orientation before irradiation. When the laser is turned on, the $<\mathrm{P}_{2}>$ values rapidly grow toward negative values because DR1 orients perpendicular to the laser polarization direction $\left(\mathrm{a}<\mathrm{P}_{2}>\right.$ value of -0.5 would indicate a perfect perpendicular orientation). A plateau, labeled $\left.<\mathrm{P}_{2}\right\rangle_{\text {max }}$, is then reached rapidly for samples with low $\mathrm{T}_{\mathrm{g}}$ ( 20 s) and after a longer irradiation time (but with a larger orientation) for high- $\mathrm{T}_{\mathrm{g}}$ samples $(\sim 120 \mathrm{~s})$. This six-fold difference in time needed to reach maximal orientation is consistent with the fact that the inscription curves in Figure 3 reach their saturation DE faster for low- $T_{g}$ samples, and with the increasing difference between the $\mathrm{DE}_{100}$ and $\mathrm{DE}_{100}$ values observed in Figure 4 with increasing $\mathrm{T}_{\mathrm{g}}$. A similar observation was made by Barrett et al. in their study of a series of $\mathrm{NO}_{2}$-functionalized azopolymers of various spacer length where lower $\mathrm{T}_{\mathrm{g}}$ samples (longer spacers) showed larger photoinduced birefringence rate constants. ${ }^{54}$ Finally, when the laser is turned off after $200 \mathrm{~s}$ of irradiation, the photo-orientation relaxes rapidly during the first few seconds and then more slowly, essentially plateauing at the end of the $120 \mathrm{~s}$ experimental relaxation timeframe. The final $\left\langle\mathrm{P}_{2}\right\rangle$ value is called the residual orientation, $<\mathrm{P}_{2}>$ res, and informs on the resistance of the material to thermally-induced motion.

Figure $6 \mathrm{~A}$ shows that the photoinduced orientation is almost zero for blends with the lowest $\mathrm{T}_{\mathrm{g}}$ and that it gradually increases with $\mathrm{T}_{\mathrm{g}}$ (with the exception of the two highest $\mathrm{T}_{\mathrm{g}}$ samples). The modest $\left\langle\mathrm{P}_{2}\right\rangle_{\max }$ value for low- $\mathrm{T}_{\mathrm{g}}$ samples is due to the important contribution of thermal relaxation during irradiation. Accordingly, the DE values recorded for these samples were very low and were not stable after irradiation because only transient gratings could form. A greater photo-orientation (and DE) is observed as $\mathrm{T}_{\mathrm{g}}$ increases, reaching a maximum value of approximately $-0.09 \pm 0.02$ for blends with a $\mathrm{T}_{\mathrm{g}}$ of $7 \mathrm{O}^{\circ} \mathrm{C}$. However, Figure $6 \mathrm{~A}$ shows that a further increase in $\mathrm{T}_{\mathrm{g}}$ is detrimental: a lower photo-orientation is observed for $\mathrm{B} 40 \%_{81}$ and $\mathrm{B} 10 \%{ }_{88}$. This decreasing orientation is not due to the incapacity of DR1 to undergo photoisomerization since the cis content under irradiation is not much affected by a high $\mathrm{T}_{\mathrm{g}}$ (Figure $2 B$ ). It thus appears that the azo moieties mainly return to their original angular distribution after trans-cis-trans cycling when the $\mathrm{T}_{\mathrm{g}}$ is too high (more than approximately 60 ${ }^{\circ} \mathrm{C}$ above the operating temperature for gDR1), which compromises their capacity to provoke anisotropic motion of the matrix through stress or generation of anisotropic free volume. These results are consistent with the observation of an optimal $\mathrm{T}_{\mathrm{g}}$ for SRG inscription where blends with a high $\mathrm{T}_{\mathrm{g}}$ showed substantially slower inscription kinetics.

Importantly, the photo-orientation results for the $\mathrm{B} 40 \%$ and $\mathrm{B} 10 \%$ blends are very similar and indicate that the DR1 orientation is almost independent of azo content for a given $\mathrm{T}_{\mathrm{g}}$. This observation is consistent with the very similar optical properties (band position, bandwidth, and minimal fraction of cis isomer under irradiation) observed for all blends in Figure 2 due to the isolation of the DR1 moieties and is reasonable because $\left\langle\mathrm{P}_{2}>\right.$ values are intrinsically normalized per azo. This result contrasts with the lower orientation that we found for azopolymer supramolecular complexes with a higher azo content, which can be explained at least in part by a concomitant change in $\mathrm{T}_{\mathrm{g}}{ }^{25}$ The trend of Figure $6 \mathrm{~A}$ also reinforces the merit of our photoactive / photopassive glass blending strategy considering that no clear conclusions could be drawn about the effect of $\mathrm{T}_{\mathrm{g}}$ on photoinduced orientation when comparing a series of molecular glasses featuring different chromophores. ${ }^{37}$

Figure 6B shows the $\left\langle\mathrm{P}_{2}\right\rangle_{\text {res }}(\%)$ (calculated as the percentage of $\left\langle\mathrm{P}_{2}\right\rangle_{\text {res }}$ with respect to $\left\langle\mathrm{P}_{2}\right\rangle_{\max }$ ) as a function of the $\mathrm{T}_{\mathrm{g}}$ of the photoactive blends. These values gradually increase in a sigmoidal-like shape from $\mathrm{o} \%$ for the lowest $\mathrm{T}_{\mathrm{g}}$ samples, where the rubbery matrix can relax quickly, to a plateau of $\sim 80 \%$ for the highest $\mathrm{T}_{\mathrm{g}}$ samples because their glassy matrix is highly viscous. As for the $\left\langle\mathrm{P}_{2}\right\rangle_{\max }$ values, 
the trend is not affected by azo content, in this case due to the fact that orientation stability mainly depends on the matrix properties. It is interesting to note that the $\left\langle\mathrm{P}_{2}\right\rangle_{\text {res }}$ plateau is reached close to the optimal $\mathrm{T}_{\mathrm{g}}$ value $\left(\sim 6 \mathrm{o}^{\circ} \mathrm{C}\right)$ observed in the SRG inscription experiments. However, in contrast with residual DE, $\left\langle\mathrm{P}_{2}>_{\text {res }}\right.$ seems to be purely temperature-dependent.
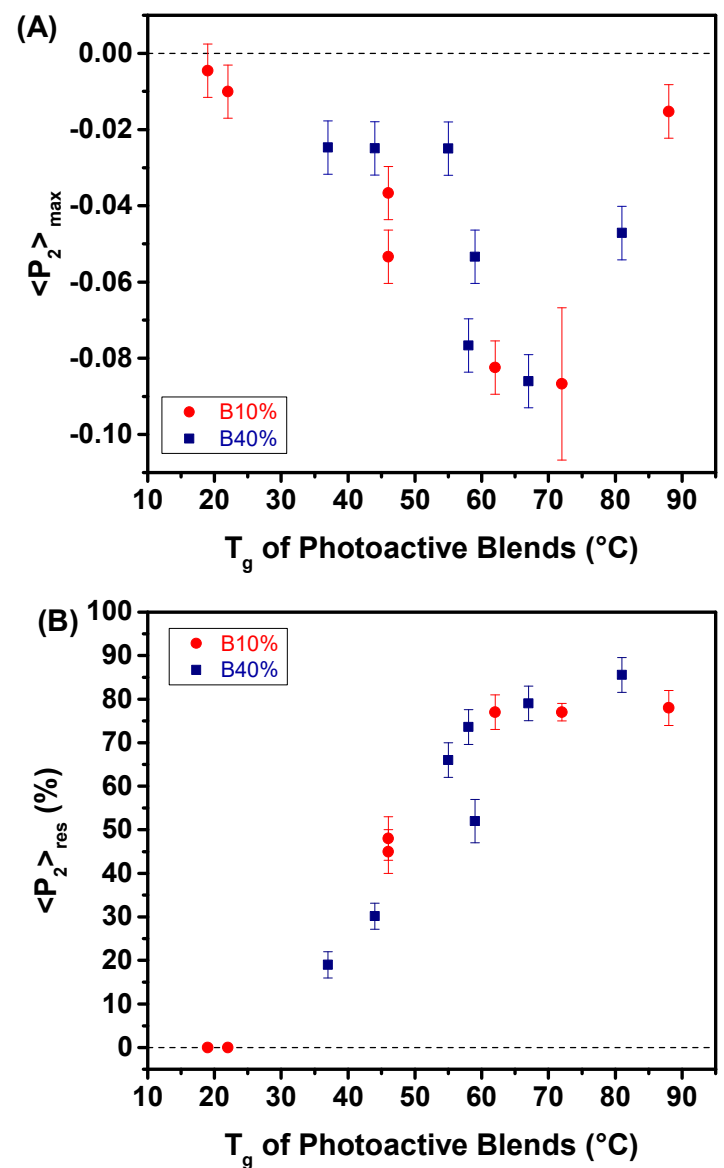

Figure 6. A) Maximal photo-orientation value $\left(<\mathrm{P}_{2}>_{\max }\right)$ and B) residual photo-orientation percentage value $\left(<\mathrm{P}_{2}\right\rangle_{\text {res }}$ percentage) of the $1104 \mathrm{~cm}^{-1}$ band of the azo moiety of gDR 1 as a function of the $\mathrm{T}_{\mathrm{g}}$ of the photoactive blends.

An important consequence of the similar DR1 orientation and orientation stability for $\mathrm{B} 40 \%$ and $\mathrm{B} 10 \%$ samples is that the cumulative orientation generated within the material is about four times larger in $\mathrm{B} 40 \%$ samples than in $\mathrm{B} 10 \%$ samples with the same $\mathrm{T}_{\mathrm{g}}$. This higher global orientation agrees very well with the higher maximal DE reached by the $\mathrm{B}_{40} \%$ blends ( $\sim 18 \%$ vs. $\left.\sim 5 \%\right)$ and also with the aforementioned requirement of a high azo content for observing an increase of DE (a residual DE > 100\%) after switching off the SRG inscription laser. In this context, it is noteworthy that the $\left\langle\mathrm{P}_{2}\right\rangle_{\max }$ value for pure gDR1 is larger ($0.12 \pm 0.02$ ) than for any of the blends, which is not surprising because its UV-visible spectrum indicated the existence of interactions between DRı units, which were absent in the blends, that can favor azo orientation. ${ }^{55}$ This larger capability to photo-orient, combined with a larger azo fraction and a similar orientation stability $\left(<\mathrm{P}_{2}>_{\text {res }} \sim 65 \%\right)$, help to explain why pure gDR 1 formed the SRG with the highest diffraction efficiency $(\sim 30 \%)$ and with the largest increase in residual DE ( 135\%) after stopping irradiation.

Our results indicate that molecular orientation and SRG DE are interconnected but that they are not directly proportional since they involve different mechanisms. The photo-orientation and SRG DE both increase with $\mathrm{T}_{\mathrm{g}}$ for low to intermediate values, irrespective of the azo content, but the trends in Figures 6 and 4 are clearly different for $\mathrm{T}_{\mathrm{g}}$ 's beyond the optimal values, where the $\mathrm{B} 40 \%$ samples show a DE plateau and the $\mathrm{B} 10 \%$ samples show a decrease in DE. It can be concluded that compounds that are not capable to orient do not have a good SRG potential, either because their $T_{g}$ is too low or too high, while those that orient do not necessarily lead to high DE values due to the inefficiency of the matrix to take advantage of the transcis-trans isomerization. In other words, the matrix needs to have an adaptation capability to be pushed anisotropically during the azo isomerization or to adapt to the angular redistribution of the azo moieties, which appears to become the kinetic limiting factor when $\mathrm{T}_{\mathrm{g}}$ exceeds the optimal value. This limited adaptability of the matrix manifests itself as large $\left\langle\mathrm{P}_{2}\right\rangle_{\text {res }}$ values that translate into slow SRG inscription rates at high $\mathrm{T}_{\mathrm{g}}$. This hypothesis implies that the optimal $\mathrm{T}_{\mathrm{g}}$ for SRG inscription involves a compromise between reaching the highest possible orientation without exceeding a certain $\left\langle\mathrm{P}_{2}>_{\text {res }}\right.$ threshold to enable anisotropic matrix motion. In this context, $\mathrm{a}<\mathrm{P}_{2}>_{\text {res }}$ of $100 \%$ would represent an extremely rigid matrix not capable of any adaptation and leading to exceedingly slow inscription kinetics. The results further indicate that it is the cumulative orientation of the chromophores (related to the product of $\left\langle\mathrm{P}_{2}\right\rangle_{\max }$ with the azo number density) that is of highest importance for SRG formation, not the orientation level of the individual azo units. This explains why blends or compounds with the same $\mathrm{T}_{\mathrm{g}}$ but with a larger relative azo content have a better potential for writing SRG with a high DE, and also why the optimal $\mathrm{T}_{\mathrm{g}}$ for high DE and fast inscription kinetics shifts to higher temperature for systems with higher azo content.

\section{CONCLUSION}

The strategy of mixing photoactive / photopassive molecular glasses allowed us to decouple for the first time the influence of two important yet often interconnected parameters, the $\mathrm{T}_{\mathrm{g}}$ and the azo content, on the photoactivity of azomaterials in order to optimize the SRG inscription process. Using this strategy, we prepared miscible photoactive blends with very similar optical properties by mixing 10 or $40 \mathrm{~mol} \%$ of a photoactive DR1-containing molecular glass with a series of its structural analogues to tune the $\mathrm{T}_{\mathrm{g}}$ between 19 and $88{ }^{\circ} \mathrm{C}$ without changing the azo content. This advantageous model system revealed that a trade-off between different parameters must be made in order to optimize SRG inscription in terms of diffraction efficiency and inscription kinetics. A high azo content (for a constant $\mathrm{T}_{\mathrm{g}}$ ) and larger photoinduced orientation (generally promoted by a high $\mathrm{T}_{\mathrm{g}}$ ) enable forming SRG with a larger DE; 
however, a high orientation stability (also encountered with high- $\mathrm{T}_{\mathrm{g}}$ materials) reflects a low matrix adaptability that slows down the kinetics of the inscription process. As a consequence, an optimal intermediate $T_{g}$ enables fast SRG inscription and maximal (saturated) DE. The optimal $\mathrm{T}_{\mathrm{g}}$ ranges between $\sim 45$ and $60^{\circ} \mathrm{C}$ for our amorphous DR1containing blends and is higher for higher azo content (and probably higher for pure DR1-containing glasses or azopolymers). For samples with a lower $\mathrm{T}_{\mathrm{g}}$, the efficient thermal relaxation of the rubbery matrix leads to very low $\mathrm{DE}$ and orientation and to limited temporal stability for both. On the other hand, for samples with higher $\mathrm{T}_{\mathrm{g}}$, the photo-orientation of the chromophore upon SRG inscription is impeded by the high viscosity of the matrix, which translates into slower kinetics and to lower DE values if the inscription time (or irradiance) is too small to reach saturation.

The results presented herein emphasize the importance of $\mathrm{T}_{\mathrm{g}}$ in amorphous systems and offer useful guidelines to optimize the choice and/or the preparation of efficient azomaterials for SRG inscription and possibly for other photoisomerization-enabled processes. Finally, it must be highlighted that the strategy of blending miscible active/passive molecular glasses, applied here to SRG inscription, is not limited to SRG or to light-responsiveness and should be broadly applicable to other types of stimuliactive/passive materials.

\section{ASSOCIATED CONTENT}

Supporting Information. $\mathrm{T}_{\mathrm{g}}$ values of the photoactive blends; Enlargement of the SRG inscription curves for B10\% samples; SRG inscription curve for pure gDRi; Initial rate of the SRG inscription curves for the $\mathrm{B} 40 \%$ samples; Representative polarized and dichroic difference PM-IRSAS spectra and photo-orientation curves. This material is available free of charge via the Internet at http://pubs.acs.org.

\section{AUTHOR INFORMATION}

\section{Corresponding Author}

*c.pellerin@umontreal.ca

\section{Note}

The authors declare no competing financial interest.

\section{Author Contributions}

The manuscript was written through contributions of all authors. / All authors have given approval to the final version of the manuscript.

\section{ACKNOWLEDGMENT}

The authors thank the Fonds de Recherche du Québec - Nature et Technologies (FRQNT, \#2012-PR-147034), the Natural Sciences and Engineering Research council of Canada (NSERC, \#312493) and the Canadian Defence Academy Research Programme (CDARP) from RMC for funding. AL thanks NSERC for a Vanier graduate scholarship. JB thanks Mercator and FAME for foreign study scholarships. JV wishes to thank FRQNT, Finnish Cultural Foundation and the Academy of Finland for postdoctoral grants. LK thanks NSERC for an undergraduate student research award.

\section{REFERENCES}

1. Kundu, P. K.; Klajn, R., Watching Single Molecules Move in Response to Light. ACS Nano 2014, 8 (12), 11913-11916.

2. Yager, K. G.; Barrett, C. J., Azobenzene Polymers for Photonic Applications. In Smart Light-Responsive Materials, Zhao, Y.; Ikeda, T., Eds. John Wiley \& Sons, Inc.: 20o8; pp 1-46.

3. Seki, T., Light-Directed Alignment, Surface Morphing and Related Processes: Recent Trends. J. Mater. Chem. C 2016, 4 (34), 7895-7910.

4. Rochon, P.; Batalla, E.; Natansohn, A., Optically Induced Surface Gratings on Azoaromatic Polymer Films. Appl. Phys. Lett. 1995, 66 (2), 136-138.

5. $\quad$ Kim, D. Y.; Tripathy, S. K.; Li, L.; Kumar, J., LaserInduced Holographic Surface Relief Gratings on Nonlinear Optical Polymer Films. Appl. Phys. Lett. 1995, 66 (10), 1166-1168.

6. Ambrosio, A.; Marrucci, L.; Borbone, F.; Roviello, A.; Maddalena, P., Light-Induced Spiral Mass Transport in AzoPolymer Films under Vortex-Beam Illumination. Nat. Commun. 2012, 3, 989.

7. Hurduc, N.; Donose, B. C.; Macovei, A.; Paius, C.; Ibanescu, C.; Scutaru, D.; Hamel, M.; Branza-Nichita, N.; Rocha, L., Direct Observation of Athermal Photofluidisation in AzoPolymer Films. Soft Matter 2o14, 10 (26), 4640-4647.

8. $\quad$ Harrison, J. M.; Goldbaum, D.; Corkery, T. C.; Barrett, C. J.; Chromik, R. R., Nanoindentation Studies to Separate Thermal and Optical Effects in Photo-Softening of Azo Polymers. J. Mater. Chem. C 2015, 3 (5), 995-1003.

9. Lefin, P.; Fiorini, C.; Nunzi, J.-M., Anisotropy of the Photo-Induced Translation Diffusion of Azobenzene Dyes in Polymer Matrices. Pure Appl. Opt. 1998, 7 (1), 71-82.

10. Barrett, C. J.; Natansohn, A. L.; Rochon, P. L., Mechanism of Optically Inscribed High-Efficiency Diffraction Gratings in Azo Polymer Films. J. Phys. Chem. 1996, 100 (21), 88368842.

11. Saphiannikova, M.; Toshchevikov, V., Optical Deformations of Azobenzene Polymers: Orientation Approach vs. Photofluidization Concept. J. Soc. Inf. Display 2015, 23 (4), 146-153. 12. Yadavalli, N. S.; Loebner, S.; Papke, T.; Sava, E.; Hurduc, N.; Santer, S., A Comparative Study of Photoinduced Deformation in Azobenzene Containing Polymer Films. Soft Matter 2016, 12 (9), 2593-2603.

13. Vapaavuori, J.; Laventure, A.; Bazuin, C. G.; Lebel, O.; Pellerin, C., Submolecular Plasticization Induced by Photons in Azobenzene Materials. J. Am. Chem. Soc. 2015, 137 (42), 1351013517 .

14. Bedrov, D.; Hooper, J. B.; Glaser, M. A.; Clark, N. A., Photoinduced and Thermal Relaxation in Surface-Grafted Azobenzene-Based Monolayers: A Molecular Dynamics Simulation Study. Langmuir 2016, 32 (16), 4004-4015.

15. Teboul, V.; Saiddine, M.; Nunzi, J.-M., IsomerizationInduced Dynamic Heterogeneity in a Glass Former below and above Tg. Phys. Rev. Lett. 2009, 103 (26), 265701.

16. Teboul, V.; Saiddine, M.; Nunzi, J.-M.; Accary, J.-B., An Isomerization-Induced Cage-breaking Process in a Molecular Glass Former below Tg. J. Chem. Phys. 2011, 134 (11), 114517.

17. Natansohn, A.; Rochon, P., Photoinduced Motions in Azo-Containing Polymers. Chem. Rev. 2002, 102 (11), 4139-4176.

18. Stumpe, J.; Kulikovska, O.; Goldenberg, L. M.; Zakrevskyy, Y., Photo-Induced Phenomena in Supramolecular Azobenzene Materials. In Smart Light-Responsive Materials, John Wiley \& Sons, Inc.: 2008; pp 47-94.

19. $\quad$ Mahimwalla, Z.; Yager, K. G.; Mamiya, J.-i.; Shishido, A.; Priimagi, A.; Barrett, C. J., Azobenzene Photomechanics: Prospects and Potential Applications. Polym. Bull. 2012, 69 (8), 967-1006. 
20. Priimagi, A.; Shevchenko, A., Azopolymer-Based Microand Nanopatterning for Photonic Applications. J. Polym. Sci., Part B: Polym. Phys. 2014, 52 (3), 163-182.

21. Nakano, H.; Tanino, T.; Takahashi, T.; Ando, H.; Shirota, Y., Relationship between Molecular Structure and Photoinduced Surface Relief Grating Formation using Azobenzene-Based Photochromic Amorphous Molecular Materials. J. Mater. Chem. 2008, 18 (2), 242-246.

22. Börger, V.; Pohle, S.; Kuliskovska, O.; GharaggozlooHubmann, K.; Stumpe, J.; Menzel, H., Azobenzene-Containing Polymers for Surface Relief Gratings. Macromol. Symp. 2009, 275$276(1), 257-265$.

23. Yesodha, S. K.; Sadashiva Pillai, C. K.; Tsutsumi, N., Stable Polymeric Materials for Nonlinear Optics: a Review Based on Azobenzene Systems. Prog. Polym. Sci. 2004, 29 (1), 45-74.

24. Priimagi, A.; Cattaneo, S.; Ras, R. H. A.; Valkama, S.; Ikkala, O.; Kauranen, M., Polymer-Dye Complexes: A Facile Method for High Doping Level and Aggregation Control of Dye Molecules. Chem. Mater. 2005, 17 (23), 5798-5802.

25. Vapaavuori, J.; Heikkinen, I. T. S.; Dichiarante, V.; Resnati, G.; Metrangolo, P.; Sabat, R. G.; Bazuin, C. G.; Priimagi, A.; Pellerin, C., Photomechanical Energy Transfer to Photopassive Polymers through Hydrogen and Halogen Bonds. Macromolecules 2015, 48 (20), 7535-7542.

26. Zhang, Q.; Wang, X.; Barrett, C. J.; Bazuin, C. G., SpacerFree Ionic Dye-Polyelectrolyte Complexes: Influence of Molecular Structure on Liquid Crystal Order and Photoinduced Motion. Chem. Mater. 2009, 21 (14), 3216-3227.

27. Wang, X.; Vapaavuori, J.; Wang, X. X.; Sabat, R. G.; Pellerin, C.; Bazuin, C. G., Influence of Supramolecular Interaction Type on Photoresponsive Azopolymer Complexes: A Surface Relief Grating Formation Study. Macromolecules 2016, 49 (13), 4923-4934.

28. Matsui, T.; Yamamoto, S.-i.; Ozaki, M.; Yoshino, K.; Kajzar, F., Relaxation Kinetics of Photoinduced Surface Relief Grating on Azopolymer Films. J. Appl. Phys. 2002, 92 (12), 69596965.

29. Veer, P. U.; Pietsch, U.; Saphiannikova, M., Time and Temperature Dependence of Surface Relief Grating Formation in Polymers Containing Azobenzene Groups with Different Dipole Moment. J. Appl. Phys. 2009, 106 (1), 014909.

30. Luca, A. R.; Moleavin, I.-A.; Hurduc, N.; Hamel, M.; Rocha, L., Mass Transport in Low Tg Azo-Polymers: Effect on the Surface Relief Grating Induction and Stability of Additional Side Chain Groups Able to Generate Physical Interactions. Appl. Surf. Sci. 2014, 290, 172-179.

31. Virkki, M.; Tuominen, O.; Kauranen, M.; Priimagi, A., Photoinduced Nonlinear Optical Response in AzobenzeneFunctionalized Molecular Glass. Opt. Express 2016, 24 (5), 49644971.

32. Veer, P. U.; Pietsch, U.; Mueller, A. D., Alteration of the Mechanical Properties of Azopolymer Film in the Process of Surface Relief Grating Formation. Appl. Phys. Lett. 2009, 94 (23), 231911.

33. Kirby, R.; Sabat, R. G.; Nunzi, J.-M.; Lebel, O., Disperse and Disordered: a Mexylaminotriazine-Substituted Azobenzene Derivative with Superior Glass and Surface Relief Grating Formation. J. Mater. Chem. C 2014, 2 (5), 841-847.

34. Bennani, O. R.; Al-Hujran, T. A.; Nunzi, J.-M.; Sabat, R. G.; Lebel, O., Surface Relief Grating Growth in Thin Films of Mexylaminotriazine-Functionalized Glass-Forming Azobenzene Derivatives. New J. Chem. 2015, 39 (12), 9162-9170.

35. Umezawa, H.; Nunzi, J.-M.; Lebel, O.; Sabat, R. G., Electric-Field-Induced Nanoscale Surface Patterning in Mexylaminotriazine-Functionalized Molecular Glass Derivatives. Langmuir 2016, 32 (22), 5646-5652.
36. Ho, M.-S.; Natansohn, A.; Barrett, C.; Rochon, P., Azo Polymers for Reversible Optical Storage. 8. The Effect of Polarity of the Azobenzene Groups. Can. J. Chem. 1995, 73 (11), 1773-1778.

37. Snell, K. E.; Hou, R.; Ishow, E.; Lagugne-Labarthet, F., Enhanced Rates of Photoinduced Molecular Orientation in a Series of Molecular Glassy Thin Films. Langmuir 2015, 31 (26), 7296-7305.

38. Snell, K. E.; Stéphant, N.; Pansu, R. B.; Audibert, J.-F.; Lagugné-Labarthet, F.; Ishow, E., Nanoparticle Organization through Photoinduced Bulk Mass Transfer. Langmuir 2014, 30 (10), 2926-2935.

39. Liang, Y.; Mauran, D.; Prud'homme, R. E.; Pellerin, C., A New Method for the Time-Resolved Analysis of Structure and Orientation: Polarization Modulation Infrared Structural Absorbance Spectroscopy. Appl. Spectrosc. 20o8, 62 (9), 941-947. 40. $\quad$ Lebel, O.; Maris, T.; Perron, M.-E.; Demers, E.; Wuest, J. D., The Dark Side of Crystal Engineering: Creating Glasses from Small Symmetric Molecules that Form Multiple Hydrogen Bonds. J. Am. Chem. Soc. 2006, 128 (32), 10372-10373.

41. Laventure, A.; Soldera, A.; Pellerin, C.; Lebel, O., Heads vs. Tails: a Double-Sided Study of the Influence of Substituents on the Glass-Forming Ability and Stability of Aminotriazine Molecular Glasses. New J. Chem. 2013, 37 (12), 3881-3889.

42. Laventure, A.; De Grandpré, G.; Soldera, A.; Lebel, O.; Pellerin, C., Unraveling the Interplay between Hydrogen Bonding and Rotational Energy Barrier to Fine-Tune the Properties of Triazine Molecular Glasses. Phys. Chem. Chem. Phys. 2016, 18 (3), 1681-1692.

43. Barrett, C.; Natansohn, A.; Rochon, P., Cis-Trans Thermal Isomerization Rates of Bound and Doped Azobenzenes in a Series of Polymers. Chem. Mater. 1995, 7 (5), 899-903.

44. Lagugné Labarthet, F.; Buffeteau, T.; Sourisseau, C., Molecular Orientations in Azopolymer Holographic Diffraction Gratings as Studied by Raman Confocal Microspectroscopy. J. Phys. Chem. B 1998, 102 (30), 5754-5765.

45. Brown, D.; Natansohn, A.; Rochon, P., Azo Polymers for Reversible Optical Storage. 5. Orientation and Dipolar Interactions of Azobenzene Side Groups in Copolymers and Blends Containing Methyl Methacrylate Structural Units. Macromolecules 1995, 28 (18), 6116-6123.

46. Goldenberg, L. M.; Gritsai, Y.; Stumpe, J., Efficient Surface Relief Grating Generated in Azobenzene-Containing Material Using an He-Ne Laser. J. Opt. 2011, 13 (7), 075601.

47. Koskela, J. E.; Vapaavuori, J.; Ras, R. H. A.; Priimagi, A., Light-Driven Surface Patterning of Supramolecular Polymers with Extremely Low Concentration of Photoactive Molecules. ACS Macro Lett. 2014, 3 (11), 1196-1200.

48. No reliable portion of the initial DE values could be chosen to estimate their initial SRG inscription rate. However, it is clear from Figure $\mathrm{S}_{1}$ that the same trend as for the $\mathrm{B}_{40} \%$ series is qualitatively present for the intermediate and high Tg blends and that the SRG inscription rates form a bell shaped curve with respect to $\mathrm{T}_{\mathrm{g}}$.

49. Yager, K. G.; Barrett, C. J., Confinement of Surface Patterning in Azo-Polymer Thin Films. J. Chem. Phys. 2007, 126 (9), 094908.

50. Lagugné Labarthet, F.; Buffeteau, T.; Sourisseau, C., Analyses of the Diffraction Efficiencies, Birefringence, and Surface Relief Gratings on Azobenzene-Containing Polymer Films. J. Phys. Chem. B 1998, 102 (15), 2654-2662.

51. del Barrio, J.; Oriol, L.; Alcalá, R.; Sánchez, C., Azobenzene-Containing Linear-Dendritic Diblock Copolymers by Click Chemistry: Synthesis, Characterization, Morphological Study, and Photoinduction of Optical Anisotropy. Macromolecules 2009, 42 (15), 5752-5760.

52. $\quad$ Wu, S.; Duan, S.; Lei, Z.; Su, W.; Zhang, Z.; Wang, K.; Zhang, Q., Supramolecular Bisazopolymers Exhibiting Enhanced 
Photoinduced Birefringence and Enhanced Stability of Birefringence for Four-Dimensional Optical Recording. J. Mater. Chem. 2010, 20 (25), 5202-5209.

53. Yager, K. G.; Tanchak, O. M.; Godbout, C.; Fritzsche, H.; Barrett, C. J., Photomechanical Effects in Azo-Polymers Studied by Neutron Reflectometry. Macromolecules 2006, 39 (26), 93119319 .

54.

Barrett, C.; Choudhury, B.; Natansohn, A.; Rochon, P., Azocarbazole Polymethacrylates as Single-Component Electrooptic Materials. Macromolecules 1998, 31 (15), 4845-4851.
55. Apitz, D.; Bertram, R. P.; Benter, N.; Hieringer, W.; Andreasen, J. W.; Nielsen, M. M.; Johansen, P. M.; Buse, K., Investigation of Chromophore-Chromophore Interaction by Electro-Optic Measurements, Linear Dichroism, X-Ray Scattering, and Density-Functional Calculations. Phys. Rev. E 2005, 72 (3), 036610. 
Table of Contents (TOC)

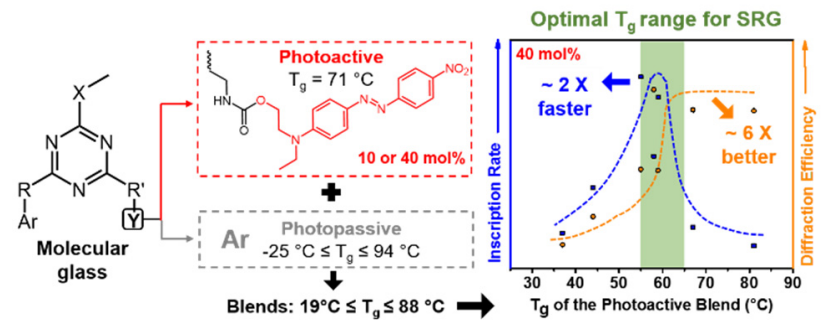

